\title{
COMPARISON OF STRONG-MOTION SPECTRA WITH TELESEISMIC SPECTRA FOR THREE MAGNITUDE 8 SUBDUCTION-ZONE EARTHQUAKES
}

\author{
By Heidi Houston and Hiroo Kanamori
}

\begin{abstract}
We studied strong-motion spectra observed for three $M_{w} 7.8$ to 8.0 earthquakes (the 1985 Michoacán, Mexico; 1985 Valparaíso, Chile; and 1983 Akita-Oki, Japan earthquakes). We determined the decay of spectral amplitude with distance from the station, considering different measures of distance from a finite fault. We compared strong-motion spectra (Fourier acceleration spectra) observed for these three earthquakes with those estimated from the source spectrum determined from teleseismic $P$ waves. We scaled the teleseismic source spectra to produce reference strong-motion spectra at periods from 1 to $10 \mathrm{sec}$ using a simple physical model of far-field $S$ body waves from a point source recorded at the surface of a homogeneous half-space. For all three earthquakes the reference spectral amplitudes at periods of 1 to $5 \mathrm{sec}$ are about half the observed ones at distances of about $50 \mathrm{~km}$. The difference increases as the distance increases. At distances of 200 to $300 \mathrm{~km}$, the reference spectrum is about $1 / 10$ of the observed one. The difference between the reference and the observed spectrum is attributed to the contribution of phases other than direct $S$ waves and to site response. We applied corrections for the finiteness (spatial extent) of the source using a simple model of rupture propagation on a dipping two-dimensional fault. Including the source finiteness did not improve the estimate substantially at periods from 1 to $20 \mathrm{sec}$, but it modeled significant changes in the signal duration as a function of azimuth for the 1985 Michoacán earthquake. Our results can be used to establish empirical relations between the observed spectra and the half-space responses, depending on the distance and the site condition. If such empirical relations can be established, source spectra determined from teleseismic records may be used to estimate strong motions.
\end{abstract}

\section{INTRODUCTION}

The nature of strong motions near a large earthquake has important implications for engineering seismology. Engineers need to know the amplitudes, durations, and frequency content of strong motions to design earthquake-resistant structures. In the past few years, three large shallow underthrusting earthquakes have produced sizable sets of strong-motion recordings. The September 19, 1985 Michoacán, Mexico $\left(M_{w}=8.0\right)$ and March 3, 1985 Valparaiso, Chile $\left(M_{w}=8.0\right)$ earthquakes occurred along the Middle America and Peru-Chile trenches, respectively. The May 26, 1983 Akita-Oki, Japan $\left(M_{w}=7.8\right)$ earthquake is interpreted as due to incipient subduction of Japan Sea lithospere under Honshu (Kanamori and Astiz, 1985). The 1985 Michoacán earthquake was recorded by the Guerrero array of digital accelerometers (Anderson et al., 1986), and the 1983 Akita-Oki and 1985 Valparaiso earthquakes were recorded by arrays of analog accelerometers. Since strong motions recorded near the fault planes of $M \approx 8$ earthquakes are rare, these strong motions are a unique and important set of records. Broadband digital teleseismic records of these earthquakes (and many others) are available from the Global Digital Seismic Network (GDSN). These broadband records contain information at periods from 1 to 30 sec. In this article we compare Fourier spectra of 
the strong motions of these earthquakes to spectra of their teleseismic motions. Our ultimate aim is to be able to estimate characteristics of strong motions from teleseismic records, since they are more numerous.

The rupture processes of these three earthquakes were significantly different. Figure 1 shows a representative broadband record, the time function, and the spatial distribution of moment release on the fault plane for each of the three earthquakes. These results were obtained by simultaneously inverting teleseismic GDSN broadband records (including long-, intermediate- and short-period seismograms) using the iterative scheme of Kikuchi and Kanamori (1982) and Kikuchi and Fukao (1987). For details, see Houston and Kanamori (1990). These results using broadband data are consistent with those of other workers using long-period WWSSN or GDSN data but resolve more short-period detail. A comparison of the seismograms and time functions in Figure 1 indicates that the three events had different frequency content. The spatial and temporal distribution of moment release on the fault plane is also different for each event. The Michoacán earthquake ruptured in two large subevents about $90 \mathrm{~km}$ and $26 \mathrm{sec}$ apart, with relatively little short-period energy. The Valparaiso earthquake consisted of one large subevent at longer periods (i.e., 15 to $50 \mathrm{sec}$ ) and several subevents radiating energy at periods of 2 to $5 \mathrm{sec}$ that cannot be located well. The Akita-Oki earthquake is an intermediate case consisting of a large relatively long-period subevent at the beginning of the rupture, followed by one or more higher frequency subevents 30 to $60 \mathrm{~km}$ north and $25 \mathrm{sec}$ later. Taken together, these results indicate that the three earthquakes ruptured with different frequency content, different spatial and temporal patterns of moment release, and different degrees of complexity of rupture. These differences presumably affected the generation of strong motions recorded near the earthquake source. An

1985 Michoacan, Mexico 1983 Akita-Oki, Japan 1985 Valparaiso, Chile
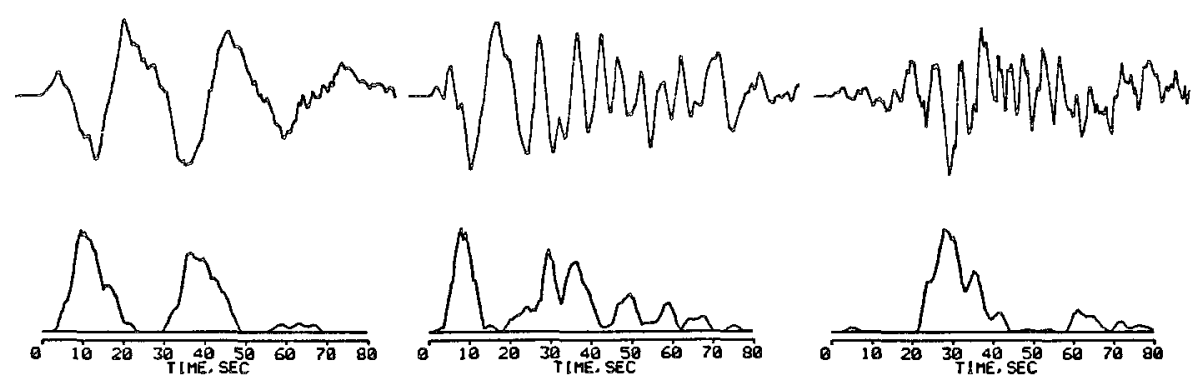

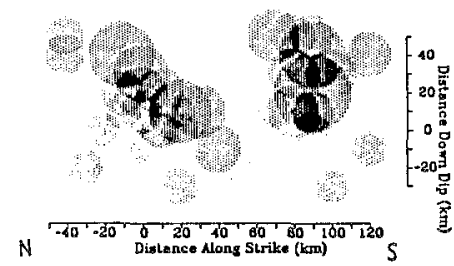

(a)

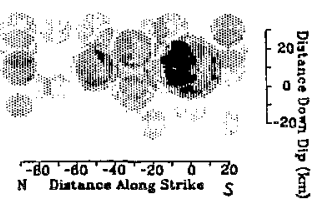

(b)

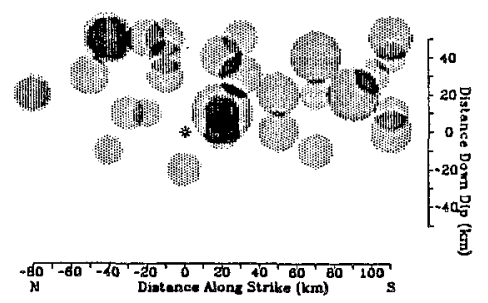

(c)

FIG. 1. Broadband teleseismic $P$ waveform from station RSNY, and the time function, and spatial distribution of moment release for each of the earthquakes studied here. (a) 1985 Michoacán, Mexico. (b) 1983 Akita-Oki, Japan. (c) 1985 Valparaíso, Chile. Modified after Houston and Kanamori (1990). For details see text. 
important question for the estimation of strong motions, therefore, is whether the differing source characteristics inferred from the teleseismic records actually can be seen in the strong motions. Because these data sets have only recently become available, a comparison of strong and teleseismic motions for such large earthquakes has not been possible before. Such a comparison has been made for the 1985 Nahanni earthquakes $\left(M_{s}=6.6,6.9\right)$ in the Northwest Territories, Canada by Choy and Boatwright (1988). Hwang and Kanamori (1989) applied the approach of Houston (1987) and this paper to the 1986 Taiwan earthquakes $\left(M_{s}=6.4,7.3\right)$.

\section{Spectral Analysis of Teleseismic Broadband Records}

Because of the complexity of such large earthquakes at periods of 1 to 30 sec, we compared strong to teleseismic motions in the spectral domain rather than the time domain. We performed a spectral analysis of the available teleseismic GDSN broadband and short-period records of the Michoacán, Akita-Oki, and Valparaiso earthquakes using the procedure described in Houston and Kanamori (1986a). We windowed, tapered, and Fourier-transformed the $P$-wave train to obtain the displacement spectrum, $\hat{u}(\omega)$. The end of the window was chosen where the amplitude dropped to about $25 \%$ of the maximum amplitude or before the phase $P P$ arrived, whichever occurred first. The moment rate spectrum, $\hat{M}(\omega)$, for each earthquake is given by:

$$
\hat{M}(\omega)=\frac{4 \pi \rho \alpha^{3} R_{E}}{g(\Delta) R_{\theta \dot{\phi}} C}\left[\frac{e^{\omega t^{*} / 2}}{\hat{I}(\omega)} \hat{u}(\omega)\right]
$$

where $\rho$ and $\alpha$ are the density and $P$-wave velocity at the source, $R_{E}$ is the radius of the earth, $g(\Delta)$ represents geometrical spreading, $R_{\theta \phi}$ is the effective radiation pattern of the $P$-wave train that includes the $P, p P$, and $s P$ phases, $C$ is the freesurface receiver effect, $t^{*}$ represents attenuation, and $I(\omega)$ is the instrument response.

In all the events studied here, the crust is involved in faulting. Hence, we took $\rho=2.8 \mathrm{~g} / \mathrm{cm}^{3}$ and $\alpha=6.5 \mathrm{~km} / \mathrm{sec}$. For $t^{*}$ we used a constant $0.7 \mathrm{sec}$. Although $t^{*}$ has been found to depend on frequency over a broad frequency range (e.g., from 0.1 to $10 \mathrm{~Hz}$ ) by various workers (Choy and Cormier, 1986; Burger et al., 1987), the regional variation in $t^{*}$ is large (Der and Lees, 1985), and it is a rather uncertain quantity. For our purposes, however, $t^{*}$ is only important between 1 and $0.5 \mathrm{~Hz}$. In view of these factors a constant $t^{*}$ of $0.7 \mathrm{sec}$ is well within the range of values found by various studies. Indeed, the conclusions of Der and Lees (1985) and Burger et al. (1987) suggest that $t^{*}$ is uncertain by $\pm .25 \mathrm{sec}$ or more. The estimate of spectral amplitude at $1 \mathrm{sec}$ would be in error by a factor of about 2 if $t^{*}$ is either 0.5 or $1 \mathrm{sec}$ instead of $0.7 \mathrm{sec}$. In order to improve the accuracy of our spectral measurements, more accurate measurements of $t^{*}$ for specific paths are necessary.

The effective radiation pattern and free-surface receiver effect $R_{\theta \phi}$ is obtained by first computing the amplitudes of the $P, p P$, and $s P$ phases at the station, and then taking the root-mean-square value. Actually, the depth phases will interfere to yield a frequency-dependent radiation pattern. But the frequency dependence is small in an average sense, especially for extended ruptures (Houston and Kanamori, 1986a).

The moment rate spectra obtained for each record are then averaged logarithmically. Figure 2 shows teleseismic acceleration source spectra $\left(\omega^{2} \hat{M}(\omega)\right)$ for the 


\section{Teleseismic Acceleration Source Spectra}
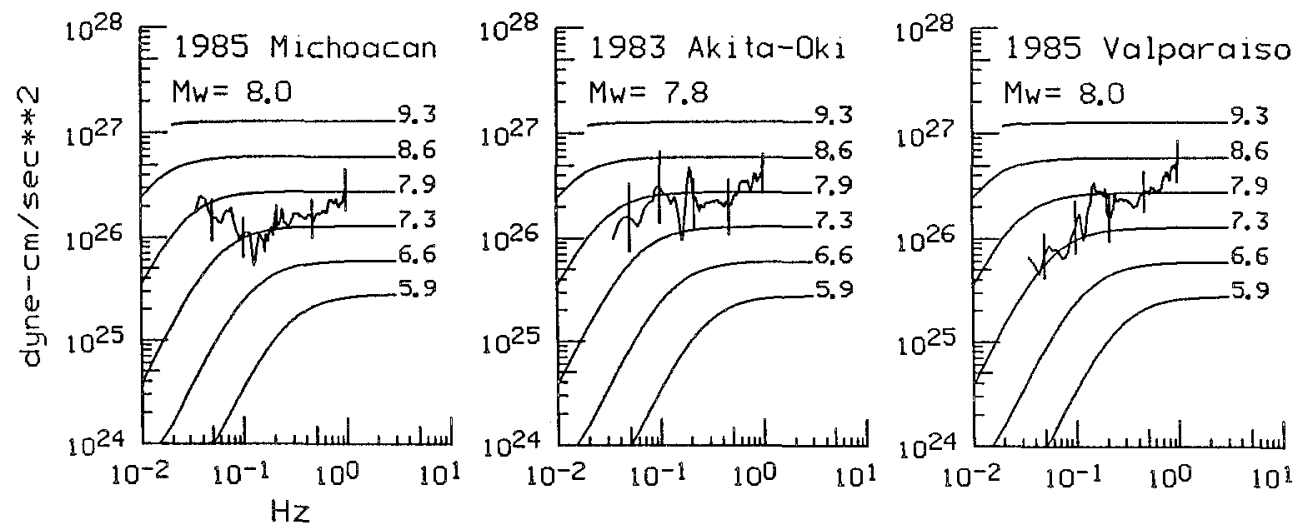

FIG. 2. Teleseismic acceleration source spectra for the 1985 Michoacán, Mexico, 1983 Akita-Oki, Japan, and 1985 Valparaiso, Chile earthquakes. The thin lines show $\omega^{-2}$ spectral models (with stress parameter 30 bars) as references. They are labeled with the appropriate moment magnitudes. The standard errors at selected frequences are shown.

Michoacán, Akita-Oki, and Valparaiso earthquakes. Clear differences exist between the teleseismic spectra of the three earthquakes, with Valparaiso having the highest and Michoacán the lowest levels between 0.5 and $1 \mathrm{~Hz}$. The Michoacán spectrum generally has the lowest level between 1 and $0.1 \mathrm{~Hz}$, despite having the largest seismic moment. This suggests a relatively smooth rupture process for the Mexican subduction zone at spatial wavelengths of 3 to $30 \mathrm{~km}$, as discussed in Houston and Kanamori (1986b).

\section{Strong-Motion Records of the Michoacán, Mexico and AKITA-OKI, JAPAN EARTHQUAKES}

The locations of the strong-motion stations used in this study are shown in Figures 3, 4, and 5. The Guerrero array in coastal Mexico is a recently installed array of digital accelerometers (Anderson et al., 1986). The strong motions of the Valparaíso earthquake were recorded by analog accelerometers operated by the Department of Civil Engineering and the Department of Geophysics at the University of Chile, Santiago. The strong motions of the Akita-Oki earthquake were gathered from analog Japanese accelerometers operated by several different institutions (Sato, 1985). For the Japanese accelerometers SAK, AKI, AOM, HAC, and MUR it was necessary to apply a correction for the SMAC-B2 instrument response (C. B. Crouse, personal communication).

Anderson et al. (1986) compared the peak accelerations of the strong motions of the Michoacán and Valparaiso earthquakes. Except in Mexico City, the peak accelerations from the Michoacán earthquake are much lower than those from the Valparaiso earthquake. The peak accelerations from the Akita-Oki earthquake are intermediate. This result is qualitatively consistent with the relative amplitudes of the teleseismic spectra in Figure 2, suggesting that source characteristics at periods of 1 to $5 \mathrm{sec}$ correlate with peak accelerations that occur at higher frequencies. Differences in the siting of accelerometers in the three regions, and differences between the frequencies shown in Figure 2 and the frequencies of the peak accelerations, may reduce the relevance of this comparison. Also, a peak measurement 


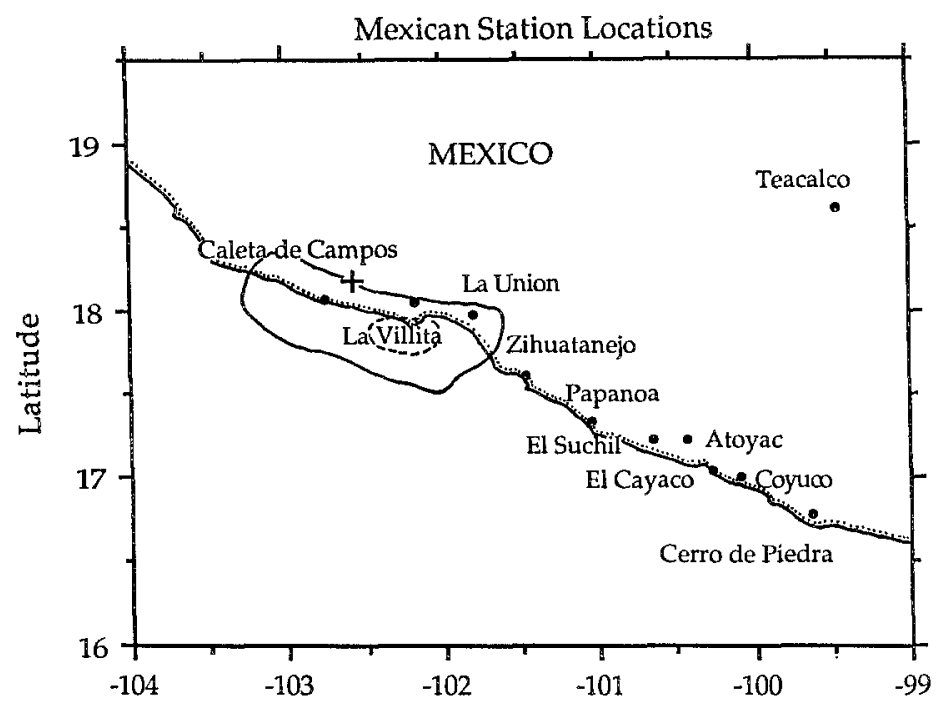

FIG. 3. Map of coastal Mexico showing strong-motion stations of the Guerrero array used in this study. The aftershock zone of the September 19, 1985 earthquake is shown. The epicenter is indicated by a plus. The aftershock zone of the 1981 Playa Azul earthquake is indicated by a dashed line.

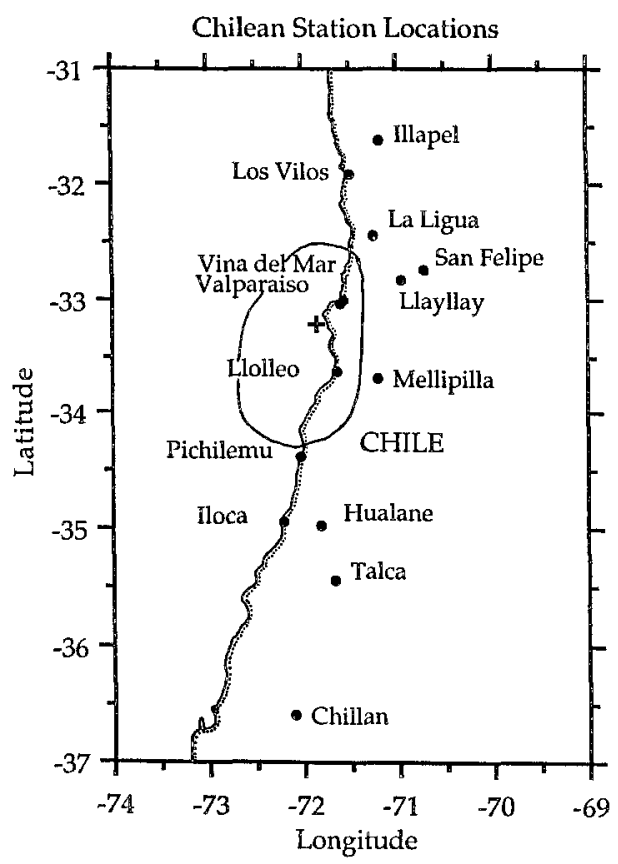

FIG. 4. Map of central Chile showing strong-motion stations used in this study. The aftershock zone of the March 3, 1985 Valparaiso earthquake is shown. The epicenter is indicated by a plus.

is not as stable as an integrated quantity, such as the spectrum. So, to make a more rigorous comparison, we will compare strong-motion spectra to teleseismic source spectra obtained above. We will need, therefore, to scale the teleseismic source spectra to obtain estimated strong-motion spectra that can be compared to the actual strong-motion spectra. First, however, we consider the decay with distance of the strong-motion data. 


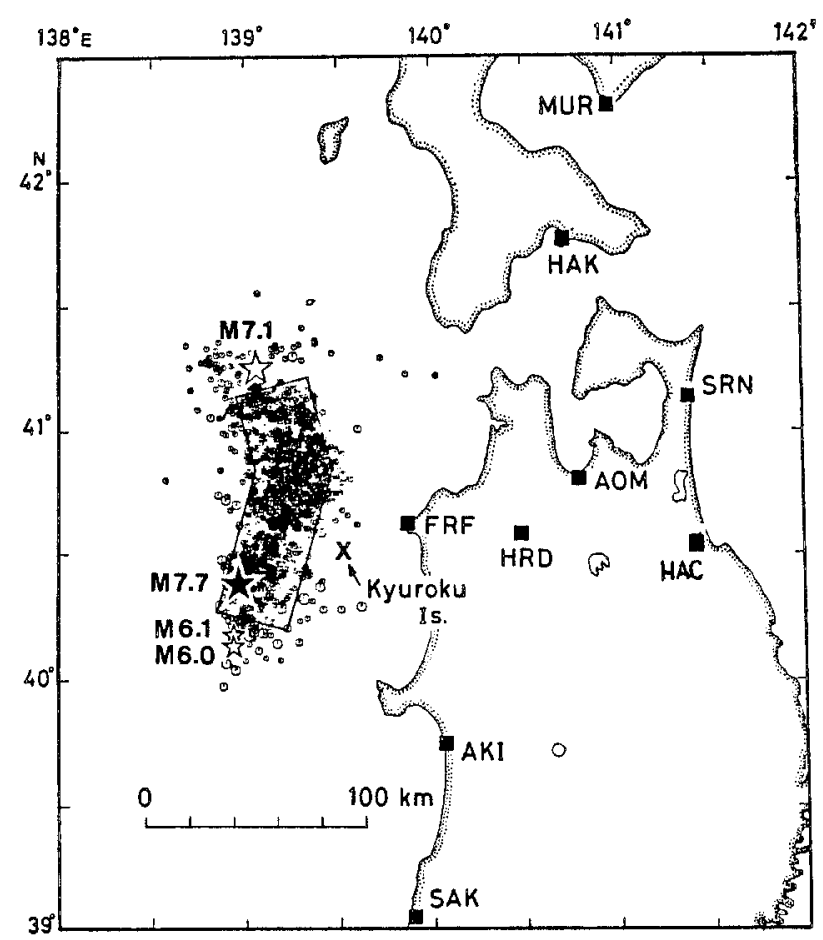

FIG. 5. Map of northern Honshu, Japan showing strong-motion stations used in this study. The distribution of aftershocks of the May 26, 1983 Akita-Oki earthquake is shown. The epicenter is indicated by a solid star. After Sato (1985).

\section{Spectral Amplitude versus Distance}

We examine how the strong motions of the 1985 Michoacán, 1985 Valparaiso, and 1983 Akita-Oki earthquakes decay with distance betewen the station and the source. Figures $6 \mathrm{a}, 7 \mathrm{a}$, and $8 \mathrm{a}$ show spectral amplitudes of ground acceleration at six frequencies versus distance from the station to the center of the fault plane for the Michoacán, Valparaíso, and Akita-Oki earthquakes, respectively. We took the square root of the sum of the squares of the spectra of the two horizontal components of acceleration at each of the stations shown in Figure 3, 4, and 5. We made a leastsquares fit between the spectral amplitudes and a power of the distance; that is, we determined $p$ and $C$ in

$$
\ddot{u}\left(f_{0}\right)=C r^{p}
$$

where $\ddot{u}\left(f_{0}\right)$ is the spectral amplitude of acceleration at a fixed frequency $f_{0}$ and $r$ is distance. Equivalently, $p$ and $\log C$ are the slope and intercept of the best-fitting line to the logarithm of spectral amplitude versus logarithm of distance:

$$
\log \ddot{u}\left(f_{0}\right)=\log C+p \log r .
$$

$p$ and $\log C$ are given in Table 1 and in the upper right-hand corner of each panel.

Figures $6 \mathrm{~b}, 7 \mathrm{~b}$, and $8 \mathrm{~b}$ compare the best-fitting lines representing amplitude versus distance for different measures of distance. The different measures of distance we compare are the distance from the station to the hypocenter, to the center of the fault plane, to the nearest point on the fault plane, and for the 
1985 Michoacan, Mexico Strong Motions

Spectral Amplitudes vs Distance to Center of Fault Plane
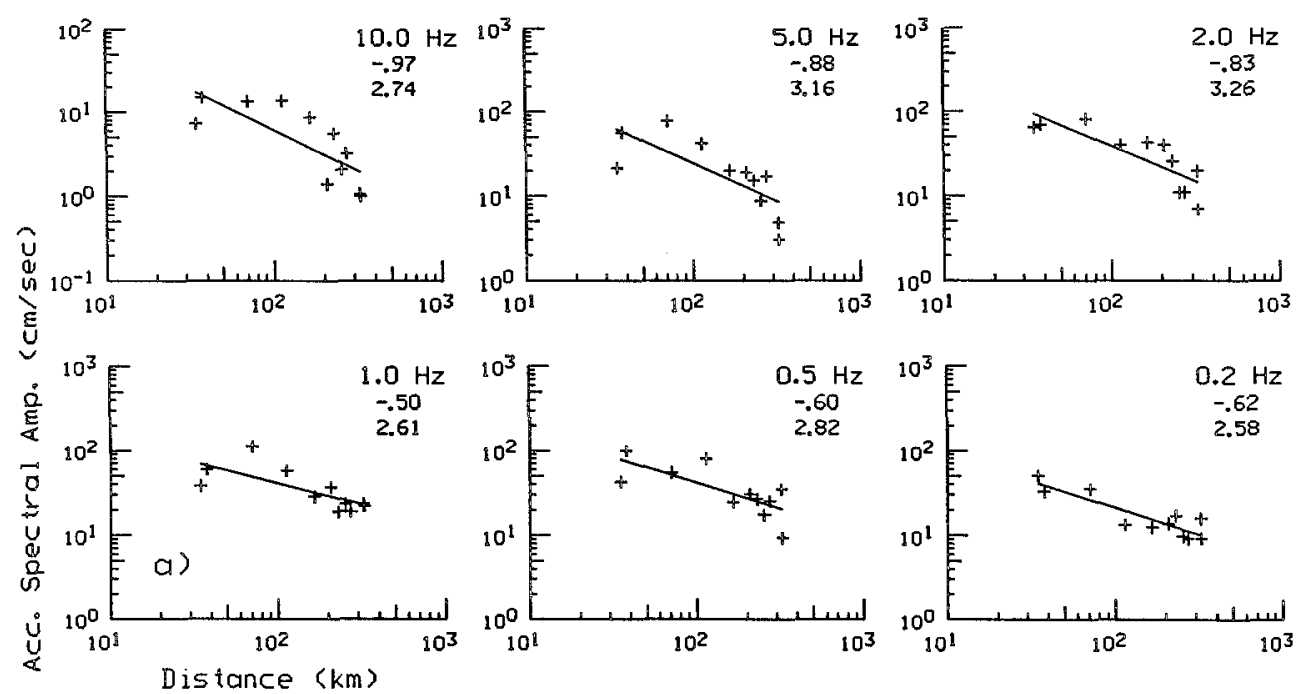

Spectral Amplitudes vs Different Measures of Distance
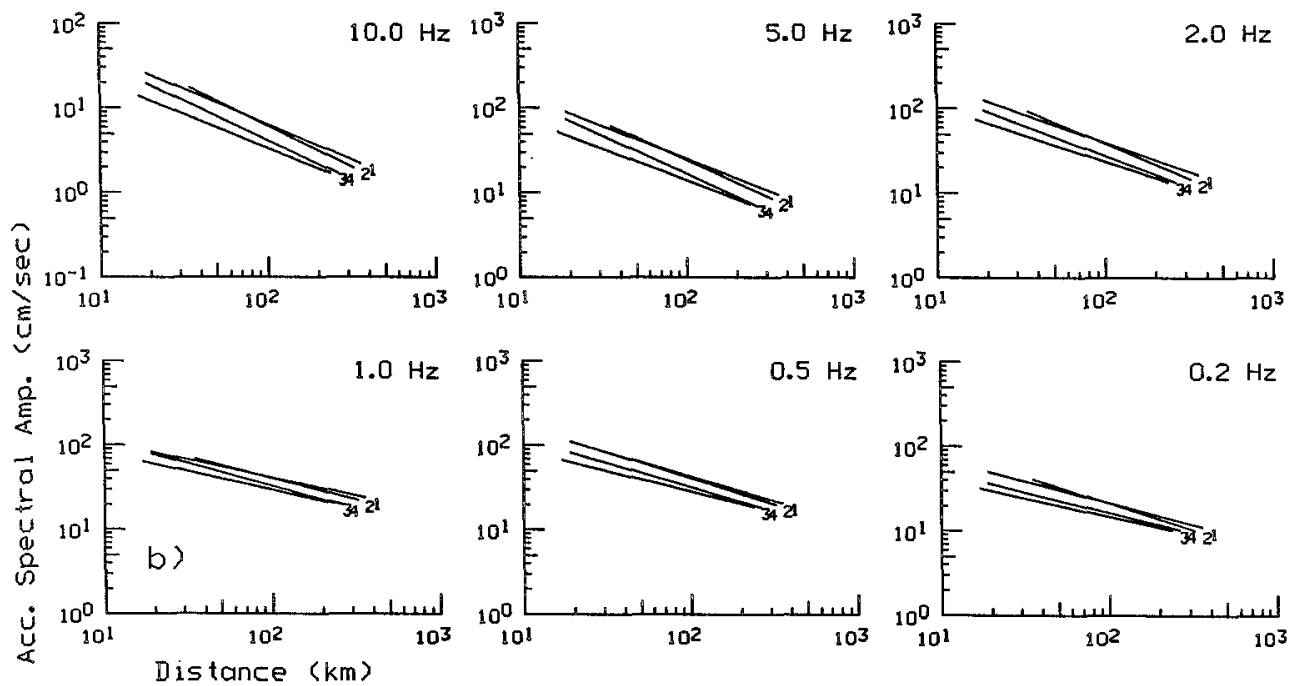

FIG. 6. Spectral amplitudes of accelerations of the 1985 Michoacán, Mexico earthquake versus distance from the source to the stations. Each panel shows spectral amplitudes at a given frequency. (a) Spectral amplitudes versus distance to the center of the fault plane. The RMS of the two horizontal components at each station is plotted. The numbers in the upper right hand corners are $p$ and $\log C$ as defined in the text. (b) A comparison of the bestfitting lines for different measures of distance between the source and the stations, including distance to the hypocenter (labeled 1), distance to the center of the fault plane (labeled 2), distance to the nearest part of the fault plane (labeled 3), and distance to the center of the nearest large asperity (labeled 4).

Michoacán event to the center of the nearest large asperity. The asperity distribution for the Michoacán earthquake used to calculate the distances to the nearest asperity in Figure 6b was obtained by Houston and Kanamori (1990) from teleseismic broadband digital $P$ waves (Figure 1). For the Michoacán earthquake the decay of spectral amplitudes with distance is quite similar for the different measures of distance; for the other two events the decay is fairly similar. In general, the decay 
1985 Valparaiso, Chile Strong Motions

Spectral Amplitudes vs Distance to Center of Fault Plane

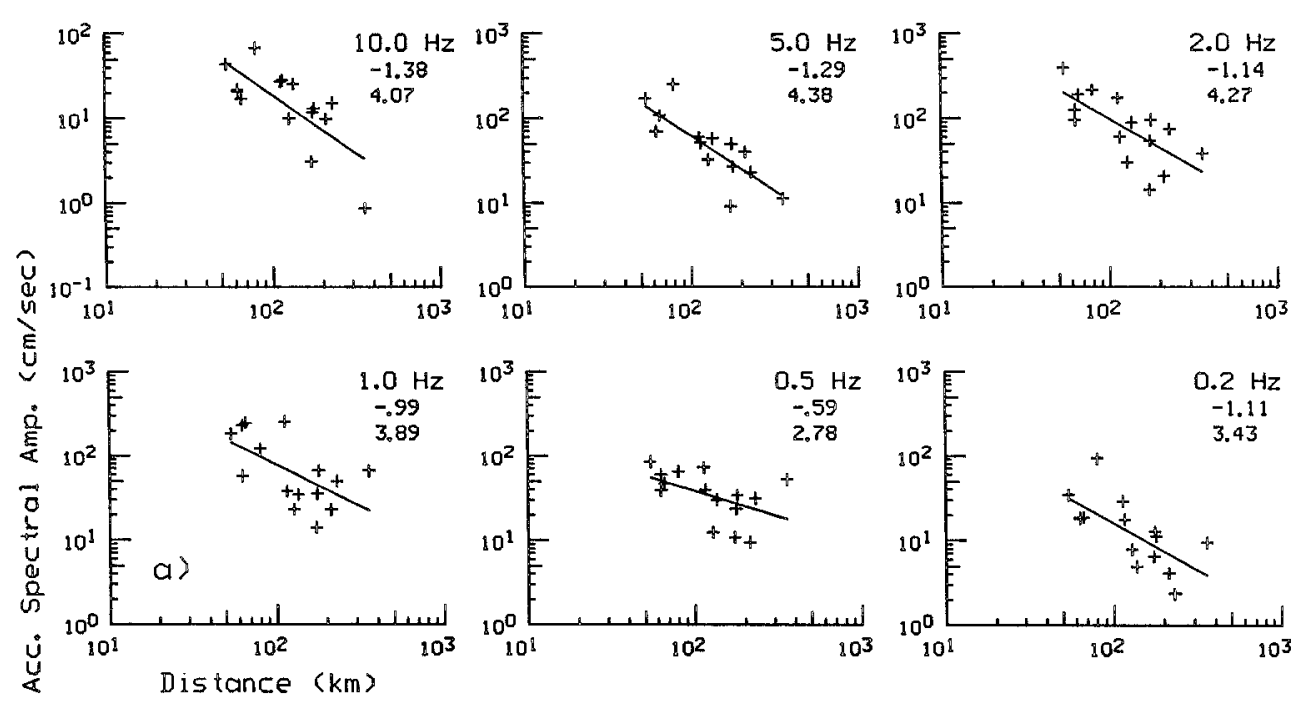

Spectral Amplitudes vs Different Measures of Distance

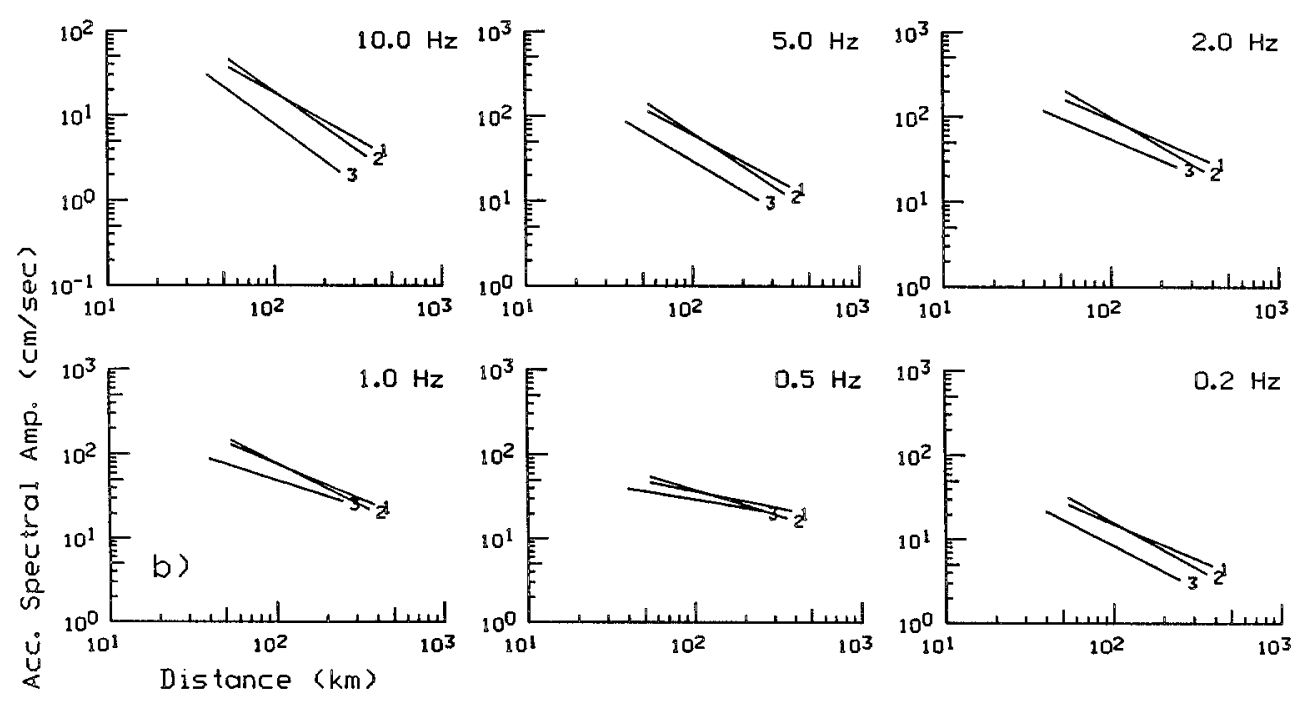

FIG. 7. Spectral amplitudes of accelerations of the 1985 Valparaiso, Chile earthquake versus distance from the source of the stations. Each panel shows the spectral amplitudes at a given frequency. (a) Spectral amplitudes versus distance to the center of the fault plane. The RMS of the two horizontal components at each station is plotted. The numbers in the upper right hand corners are $p$ and $\log C$ as defined in the text. (b) A comparison of the bestfitting lines for different measures of distance between the source and the stations, including distance to the hypocenter (labeled 1), distance to the center of the fault plane (labeled 2), and distance to the nearest part of the fault plane (labeled 3).

of amplitude versus distance to the center of the fault plane is intermediate between the other measures of distance.

Figure 9 directly compares spectral amplitude versus distance to the center of the fault plane for the three earthquakes. Attenuation with distance is quite different between the three subduction zones. The reasons for this are unclear; however, the site responses are not the same for the three sets of data. The strong motions of 
1983 Akita-Oki, Japan Strong Motions

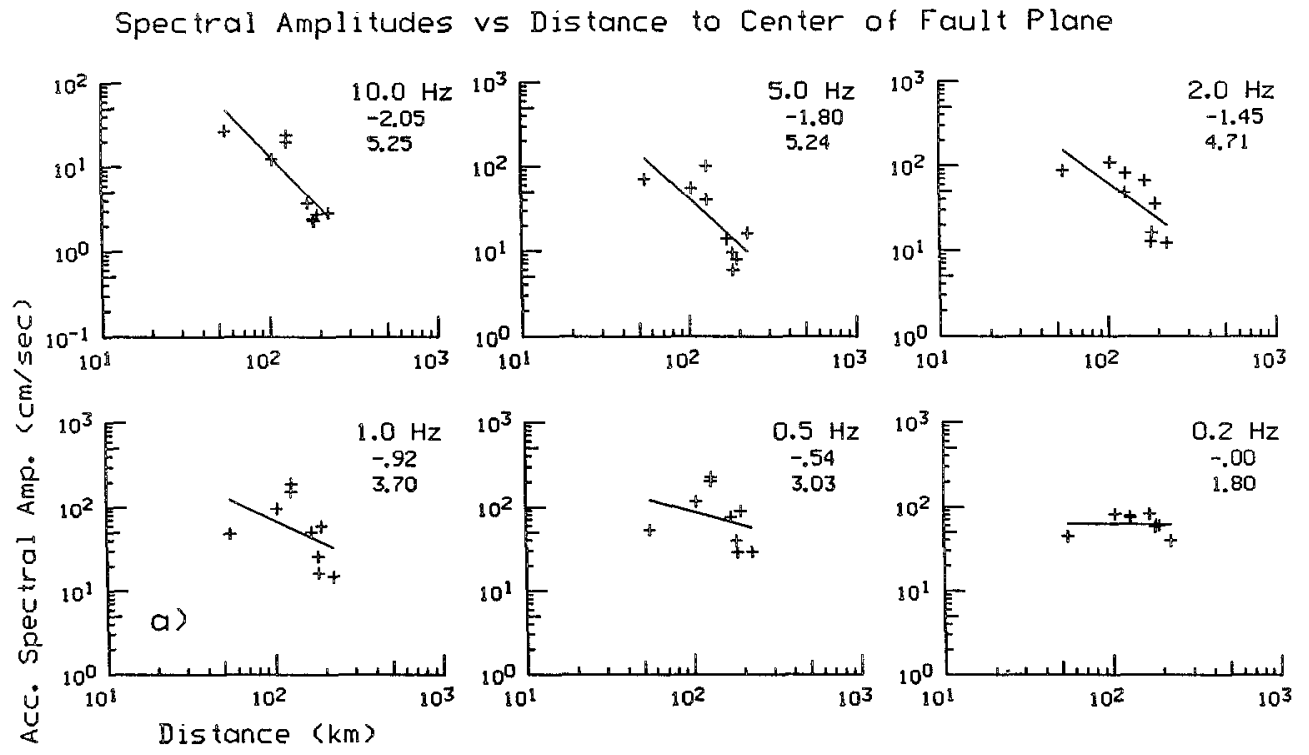

Speciral Amplitudes vs Different Measures of Distance
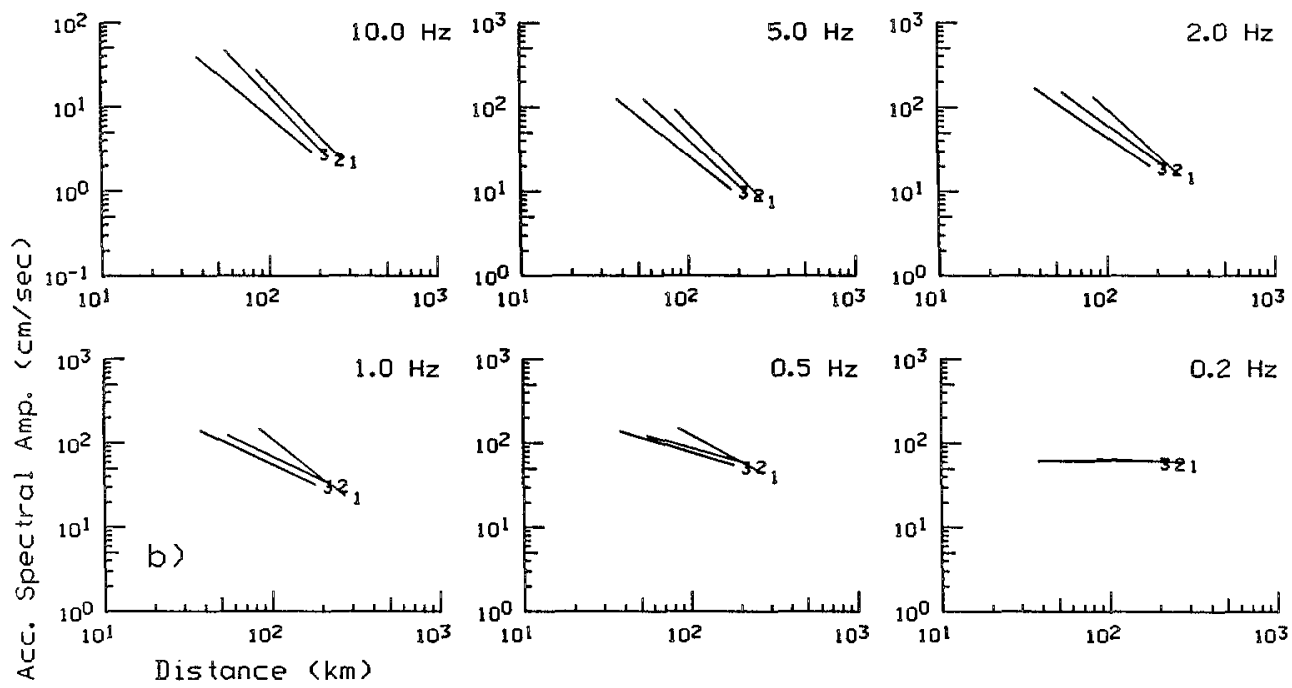

FIG. 8. Spectral amplitudes of accelerations of the 1983 Akita-Oki, Japan earthquake versus distance from the source to the stations. Each panel shows the spectral amplitudes at a given frequency. (a) Spectral amplitudes versus distance to the center of the fault plane. The RMS of the two horizontal components at each station is plotted. The numbers in the upper right hand corners are $p$ and $\log C$ as defined in the text. (b) A comparison of the best-fitting lines for different measures of distance between the source and the stations, including distance to the hypocenter (labeled 1), distance to the center of the fault plane (labeled 2), and distance to the nearest part of the fault plane (labeled 3).

the Michoacán earthquake generally have a lower absolute amplitude for a given distance and a slower decay with distance than those of the Valparaiso and AkitaOki earthquakes. At 10,5, and $2 \mathrm{~Hz}$ the Valparaiso and Akita-Oki strong motions are about equal and larger than those of Michocan. At $0.5 \mathrm{~Hz}$, however, the AkitaOki strong motions are largest, with those of Michoacán and Valparaiso about equal. These levels at 1 and $0.5 \mathrm{~Hz}$ are not completely consistent with the relative 
TABLE 1

DeCay of SPECTRAL AMplitudes with Distance

\begin{tabular}{|c|c|c|c|c|c|c|c|c|c|c|c|c|}
\hline \multirow{2}{*}{$\begin{array}{l}\text { Distance from } \\
\text { station to: }\end{array}$} & \multicolumn{2}{|c|}{$10 \mathrm{~Hz}$} & \multicolumn{2}{|c|}{$5 \mathrm{~Hz}$} & \multicolumn{2}{|c|}{$2 \mathrm{~Hz}$} & \multicolumn{2}{|c|}{$1 \mathrm{~Hz}$} & \multicolumn{2}{|c|}{$0.5 \mathrm{~Hz}$} & \multicolumn{2}{|c|}{$0.2 \mathrm{~Hz}$} \\
\hline & $p$ & $\log C$ & $p$ & $\log C$ & $p$ & $\log C$ & $p$ & $\log C$ & $p$ & $\log C$ & $p$ & $\log C$ \\
\hline \multicolumn{13}{|c|}{1985 Michoacán, Mexico earthquake } \\
\hline Hypocenter & -0.83 & 2.48 & -0.76 & 2.94 & -0.69 & 2.98 & -0.41 & 2.45 & -0.56 & 2.76 & -0.51 & 2.35 \\
\hline $\begin{array}{l}\text { Center of } \\
\text { fault plane }\end{array}$ & -0.97 & 2.74 & -0.88 & 3.16 & -0.83 & 3.26 & -0.50 & 2.61 & -0.60 & 2.82 & -0.62 & 2.58 \\
\hline $\begin{array}{l}\text { Closest part of } \\
\text { fault plane }\end{array}$ & -0.80 & 2.13 & -0.74 & 2.63 & -0.64 & 2.66 & -0.43 & 2.34 & -0.47 & 2.41 & -0.43 & 2.03 \\
\hline $\begin{array}{l}\text { Center of closest } \\
\text { large asperity }\end{array}$ & -0.93 & 2.48 & -0.89 & 3.02 & -0.73 & 2.92 & -0.52 & 2.57 & -0.56 & 2.64 & -0.47 & 2.17 \\
\hline \multicolumn{13}{|c|}{1985 Valparaiso, Chile earthquake } \\
\hline Hypocenter & -1.10 & 3.48 & -1.04 & 3.86 & -0.84 & 3.66 & -0.82 & 3.54 & -0.39 & 2.34 & -0.84 & 2.88 \\
\hline $\begin{array}{l}\text { Center of } \\
\text { fault plane }\end{array}$ & -1.38 & 4.07 & -1.29 & 4.38 & -1.14 & 4.27 & -0.99 & 3.89 & -0.59 & 2.78 & -1.11 & 3.43 \\
\hline $\begin{array}{l}\text { Closest part of } \\
\text { fault plane }\end{array}$ & -1.45 & 3.80 & -1.15 & 3.79 & -0.84 & 3.42 & -0.63 & 2.96 & -0.32 & 2.12 & -1.04 & 3.01 \\
\hline \multicolumn{13}{|c|}{1983 Akita-Oki, Japan earthquake } \\
\hline Hypocenter & -2.10 & 5.50 & -2.08 & 5.99 & -1.84 & 5.68 & -1.55 & 5.17 & -1.06 & 4.23 & -0.07 & 1.95 \\
\hline $\begin{array}{l}\text { Center of } \\
\text { fault plane }\end{array}$ & -2.05 & 5.25 & -1.80 & 5.24 & -1.45 & 4.71 & -0.92 & 3.70 & -0.54 & 3.03 & 0.00 & 1.80 \\
\hline $\begin{array}{c}\text { Closest part of } \\
\text { fault plane }\end{array}$ & -1.64 & 4.20 & -1.57 & 4.58 & -1.34 & 4.35 & -0.92 & 3.61 & -0.58 & 3.06 & 0.01 & 1.77 \\
\hline
\end{tabular}

Spectral Amplitudes vs Distance to Center of Fault Plane Michoacan, Valparaiso, Akita-Oki Ear thquakes

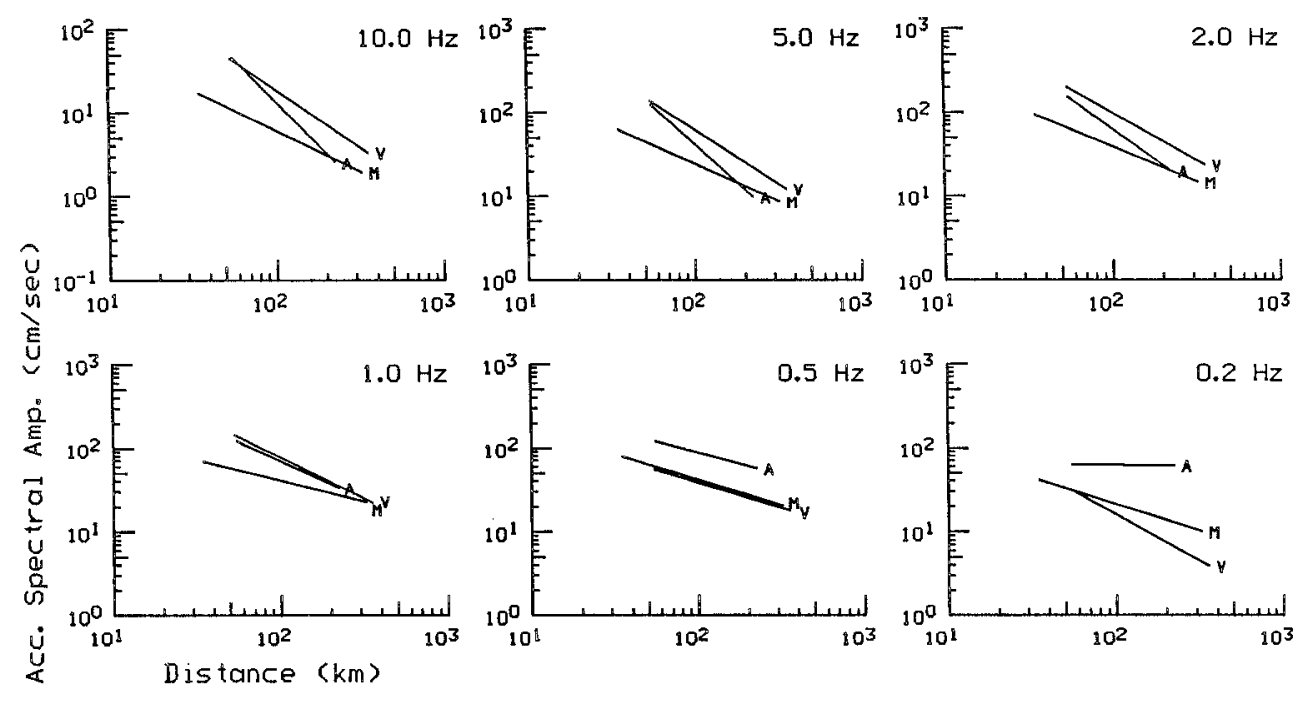

FIG. 9. Comparison of the decay of amplitude with distance for the 1985 Michoacan, Mexico, 1985 Valparaiso, Chile, and 1983 Akita-Oki, Japan earthquakes, labeled M, V, and A, respectively. The measure of distance used is the distance from the center of the fault plane to the station. Each panel shows the decay with distance at a given frequency. 
levels of the teleseismic source spectra seen in Figure 2, which would have Valparaiso highest, then Akita-Oki, then Michoacán. Of course, this inconsistency could result from different average site responses for the three sets of accelerometers, as well as different $Q$ structures. It is not clear why the Akita-Oki spectral levels fall off so rapidly with distance at high frequencies and so slowly at low frequencies. There could be some noise contamination at the lowest frequencies. The Japanese strongmotion stations are a more heterogeneous group, since stations are operated by several different institutions. The decay with distance $r$ expected for body waves is $(1 / r) e^{-\omega r / 2 Q \beta}$. At 1 and $0.5 \mathrm{~Hz}$, the decay of the Michoacán strong motions is about $1 / r^{0.5}$. Presumably, this slow decay is due to the geometric effect of the large fault plane for the nearby stations and the development of surface waves at the farther stations, especially at low frequencies. The slow decay is consistent with the decay of peak ground motions for large earthquakes shown in Figures $19 \mathrm{~h}, 20 \mathrm{~h}$, and $21 \mathrm{~h}$ of Heaton et al. (1986).

Since we want to interpret the results in the framework of geometrical spreading in a half-space, it is advisable to choose a physically meaningful distance. For large earthquakes, it is desirable to use a more physically significant distance than the distance to the hypocenter. Different distance measures should be used for different purposes. Distance to the nearest point on the fault plane may be reasonable for peak values, like peak acceleration. However, distance to the center of the fault plane or to the nearest large asperity (if known) seems physically more reasonable for integrated quantities such as spectra. We use the distance from the station to the center of the fault plane to scale teleseismic source spectra below.

\section{Estimating Strong-Motion Spectra from Teleseismic Spectra}

\section{Point Source Model}

Strong ground motions are controlled by many factors, including the earthquake source, path effects, and site effects. In order to assess these effects, accurate knowledge of the crustal structure and site geology is necessary. Very often, however, the structure is not known in sufficient detail. Even if the structure were known, the propagation of high-frequency waves is so complex that accurate estimation would be difficult. Under these circumstances, we take the following approach. The strong-motion acceleration spectra cannot be directly compared with the teleseismic souce spectra. Our ultimate objective is to use the source spectra determined from teleseismic data to estimate strong motions in the epicentral area (i.e., at distances up to approximately $300 \mathrm{~km}$ ). In order to estimate path and site effects, we want to compare the observed strong-motion spectra with spectra which would have been observed from a simple structural model that has no significant path and site effects. Therefore, we use a simple physical model of $S$ waves in a half-space to calculate a reference strong-motion spectrum from the teleseismic source spectrum. The spectrum thus calculated should be considered a reference spectrum; it is not a realistic estimate of the acceleration spectrum at a specific site but is a standard against which the observed spectrum is compared. Any difference from the reference spectrum is attributed to path and site effects. The path effect depends on the distance, and the site effect on the geology of the individual station (e.g., hard-rock site versus soil or alluvial site). If we can establish some empirical relations between the observed and reference spectra, the distance, and the site condition, then we can use them to estimate strong ground motions from the far-field spectrum as a function of distance and the site condition. Eventually, expected regional differences in the earthquake source spectrum can be included. 
Under the assumption that the strong motions consist of far-field $S$ waves from a point source recorded on the surface of a uniform half-space, the reference $S$-wave acceleration spectrum, $\ddot{u}_{\mathrm{sm}}(\omega)$, is given by

$$
\ddot{u}_{\mathrm{sm}}(\omega)=\frac{R_{\theta \phi}^{S} C^{S}}{4 \pi \rho \beta^{3} r_{0}} e^{-\omega r_{0} / 2 Q \beta} \omega^{2} \hat{M}(\omega) .
$$

where $\rho$ and $\beta$ are the density and $S$-wave velocity at the source, $r_{o}$ is the distance between the station and the source (center of the fault plane), $R_{\theta \phi}^{S}$ is the radiation pattern of $S$ waves, $C^{S}$ is the free-surface receiver effect, and $Q$ is the quality factor.

In equation (2) we take $\beta=3.8 \mathrm{~km} / \mathrm{sec}$, and $\rho=2.8 \mathrm{~g} / \mathrm{cm}^{3}$, which are consistent with the $P$-wave velocity and density used in the teleseismic analysis in equation (1). $Q$ is assumed to be 300 . Although $Q$ is actually a function of frequency, it is very uncertain and may well be different for the three subduction zones considered here. The teleseismic source spectrum is only known (and the reference spectrum only computed) from 30 to $1 \mathrm{sec}$; so, for this application, $Q$, which is uncertain and varies regionally, is not too important. A study by Castro et al. (1990) indicates that $Q$ near the Mexican subduction zone is about 300 at $1 \mathrm{~Hz}$. We take $C^{S}=2$ to account for the free-surface effect for $\mathrm{SH}$ waves, and $R_{\theta \phi}^{S}=0.63$, the value of the $S$ radiation pattern averaged over the entire focal sphere (Brune, 1970). Under "Discussion" below, we demonstrate that the use of an average radiation pattern is justified.

We compare the estimated acceleration spectra with the observed spectra for the Michoacán, Valparaíso, and Akita-Oki earthquakes in Figures 10, 11, and 12. We note that the digital strong-motion data from the Guerrero array in Figure 10 are still reliable at frequencies as low as $0.05 \mathrm{~Hz}$ (J. Anderson, personal communication). The observed spectra in Figures 11 and 12 are reliable only down to frequencies of about $0.2 \mathrm{~Hz}$, because they were obtained from analog records.

Generally, the reference spectra are less than the observed ones, with the difference increasing from factors of less than or about 2 at the closer stations to factors of 10 at the most distant stations. Of course, the differences must be due to complex path and site effects, which were not included. Correlations between site effects and the spectra will be discussed in the Discussion section below. A noticeable effect for all three earthquakes is the increasing difference between the estimated and observed accelerations with distance, which is probably largely due to the development of phases other than direct $S$ waves (e.g., surface waves).

\section{Correction for Source Finiteness}

In the comparison above we assumed a point source and ignored the spatial extent of the source. For stations near the fault plane, the effect of receiving radiation from a spatially extended fault plane rather than from a point source may be important. From Figure 3, it appears that this geometric effect may be important for stations Caleta de Campos, La Villita, La Union, and Zihuatanejo in Mexico, which sit just above the large fault plane of the Michoacán earthquake. Therefore, we have developed an approach that corrects the right-hand side of equation (2) for the effect of an extended fault plane with a specified heterogeneous distribution of moment and applied the approach to these four stations. We did not apply this 
1985 Michoacan, Mexico Strong Motion Spectra
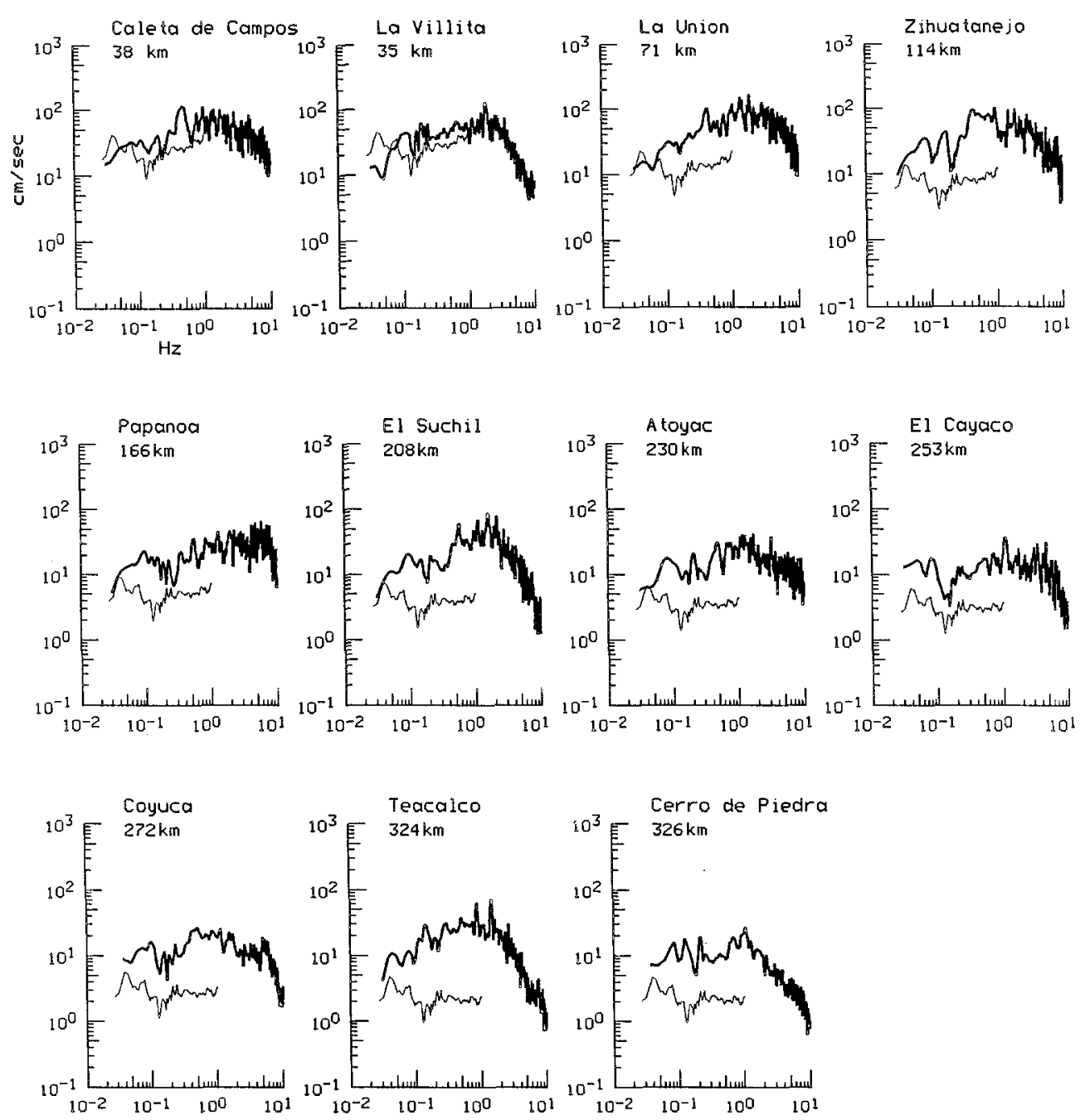

FIG. 10. Fourier acceleration spectra of the 1985 Michoacán, Mexico earthquake. The thick lines show the spectra of the strong-motion data. The thin lines show the acceleration spectra estimated from the teleseismic source spectrum assuming a point source. The distance shown in the upper-left corner of each panel is the distance from the station to the center of the fault plane used in equation (2). The discrepancy between the strong-motion data and our estimate from teleseismic data becomes larger at greater distances probably because of the increasing contribution of phases other than direct $S$ waves.

correction to any Chilean stations, because the detailed distribution of moment release on the fault plane is not known reliably for the Valparaiso earthquake, and it probably is important for the strong motions.

Our approach is to construct two time series that we call rupture functions which contain the basic effects of rupture propagating over a two-dimensional finite fault with a heterogeneous distribution of moment for the two cases of a strong-motion $S$ wave and a teleseismic $P$ wave. We construct rupture functions $A_{\mathrm{sm}}(t)$ and $A_{\text {tele }}(t)$ for strong-motion stations and teleseismic stations, respectively, as follows. We 


\section{Valparaiso. Chile Strong Motion Spectra}
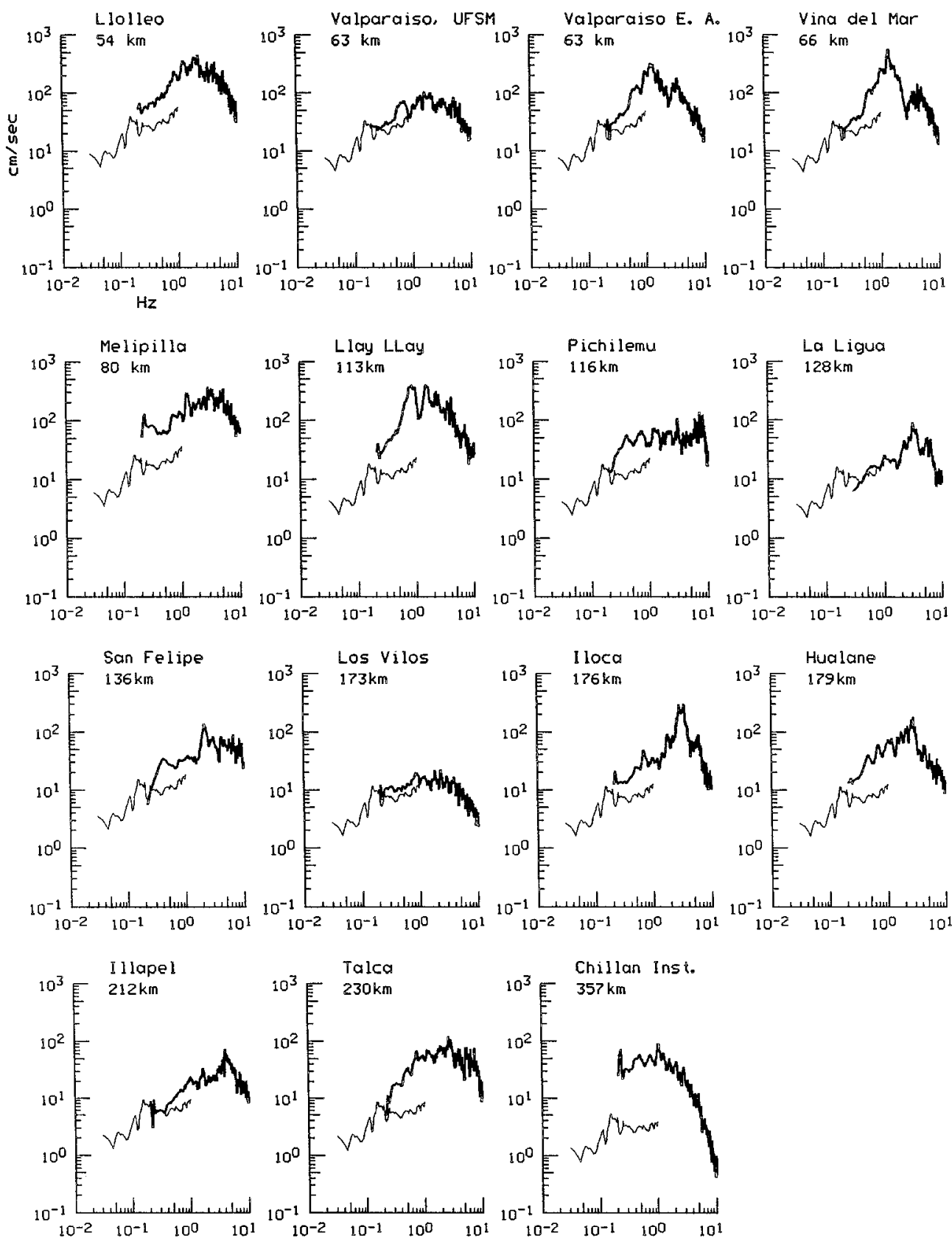

FIG. 11. Fourier acceleration spectra of the 1985 Valparaiso, Chile earthquake. See caption for Figure 10 . 
1983 Akita-Oki, Japan Strong Motion Spectra
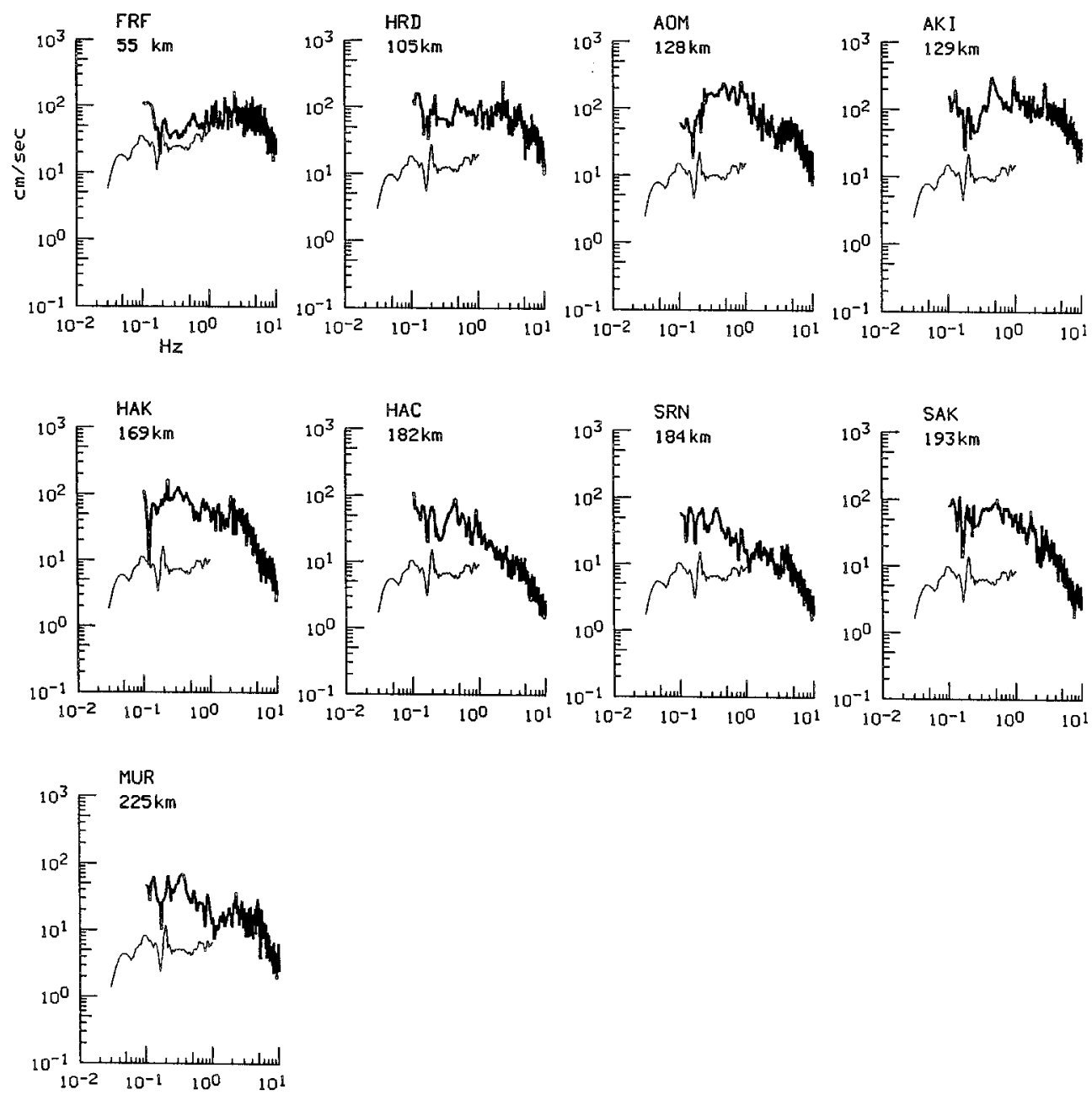

FIG. 12. Fourier acceleration spectra of the 1983 Akita-Oki, Japan earthquake. See caption for Figure 10 .

divide the finite fault into subfaults to which seismic moment $m_{i j}$ is assigned, where $i$ and $j$ represent length and width of the fault.

$$
\begin{aligned}
& A_{\mathrm{sm}}(t)=\sum_{i j} m_{i j} \frac{r_{\mathrm{o}}}{r_{i j}} \frac{R_{i j}^{S}}{R_{\theta \phi}^{S}} \delta\left(t-t_{i j}-\frac{r_{i j}}{\beta}\right) \\
& A_{\text {tele }}(t)=\sum_{i j} m_{i j} \frac{1}{R_{\theta \phi}}\left[R^{P} \delta\left(t-t_{i j}\right)+R^{p P} \delta\left(t-t_{i j}-\tau_{i j}^{p P}\right)+R^{s P} \delta\left(t-t_{i j}-\tau_{i j}^{s P}\right)\right]
\end{aligned}
$$

where $r_{i j}$ is the distance from the $i j$ th subfault to the strong-motion station, and $t_{i j}$ is the time when the $i j$ th subfault ruptures. $\tau_{i j}^{P P}$ and $\tau_{i j}^{s P}$ are the times between the arrival of $P$ and the arrivals of the depth phases $p P$ and $s P$ and thus depend on the 
depth of the $i j$ th subfault. $R_{i j}^{S}$ is the $S$ radiation pattern coefficient appropriate for the ijth subfault. $R^{P}, R^{p P}$, and $R^{s P}$ are the $P, p P$, and $s P$ radiation pattern coefficients. We assume that the distance from each subfault to the teleseismic station is the same. The effect of the finite fault on attenuation is not included, because to do so would increase significantly the complexity and cost of the calculations. Attenuation is still included in an average sense in equation (4). Figure 13 shows examples of $A_{\mathrm{sm}}(t)$ for the four stations and an example of $A_{\text {tele }}(t)$.

Let $\dot{A}_{\mathrm{sm}}(\omega)$ and $\hat{A}_{\text {tele }}(\omega)$ be the Fourier transforms of $A_{\mathrm{sm}}(t)$ and $A_{\text {tele }}(t)$, respectively. To modify $\hat{M}(\omega)$ so that it represents the moment rate spectrum of a finite source appropriate to nearby stations, we first divide $\hat{M}(\omega)$ by $\dot{A}_{\text {tele }}(\omega)$ to remove the effect of the extended rupture on the teleseismic spectrum and then multiply by $\dot{A}_{\text {sm }}(\omega)$ to include the effect on the strong-motion spectrum. Thus we obtain, corresponding to $(2)$,

$$
\ddot{u}_{\mathrm{sm}}(\omega)=\frac{R_{\theta \phi}^{S} C^{S}}{4 \pi \rho \beta^{3} r_{\mathrm{o}}} e^{-\omega r_{o} / 2 Q \beta} \omega^{2} \hat{M}(\omega) \frac{\hat{A}_{\mathrm{sm}}(\omega)}{\hat{A}_{\text {tele }}(\omega)}
$$

We assume that the rupture starts from the hypocenter and propagates radially with a variable rupture velocity chosen from a random Gaussian distribution. Then $t_{i j}$ is calculated by dividing the distance from the hypocenter to the $i j$ th subfault by the rupture velocity chosen for that subfault. This distribution of $t_{i j}$ implies that the local variation of time of rupture of a subfault increases with distance from the hypocenter, which is not unexpected and was found to be the case for the $\mathbf{1 9 8 6}$ Andreanof Islands earthquake by Houston and Engdahl (1989). We can include asperities in this model by choosing the subfault moment $m_{i j}$ from one of two Gaussian distributions which represent weak and strong subfaults. For a more complete discussion of this model see Houston and Kanamori (1986a), who used this model of rupture to simulate strong motions from five great earthquakes.

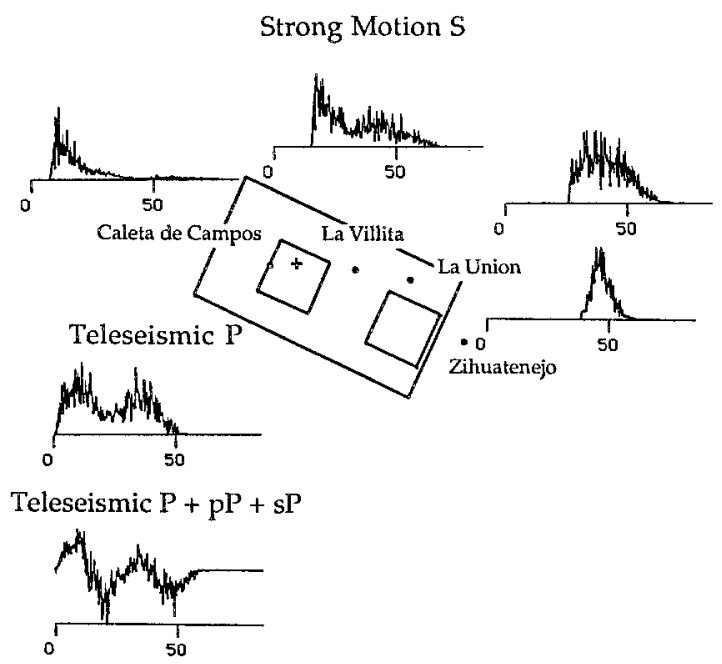

FIG. 13. Schematic of the simulation to include the effect of an extended source for the 1985 Michoacán, Mexico earthquake. The location of the assumed fault plane with two large asperities is shown. Examples of the functions $A_{\mathrm{sm}}(t)$ and $A_{\text {tele }}(t)$ (which include $P+p P+s P$ ) defined in equation (3) and used in equation (4) to correct for a finite fault are shown. Examples of $A_{\mathrm{sm}}(t)$ are shown for the stations Caleta de Campos, La Villita, La Union, and Zihuatenejo. The hypothetical teleseismic station is located in an azimuth perpendicular to the strike of the fault. 
To simulate the rupture of the 1985 Michoacán earthquake, a fault plane of 170 by $80 \mathrm{~km}$ is divided into 2 by 2 -km subfaults. Each subfault acts as a point source with focal mechanism $\phi=295^{\circ}, \delta=15^{\circ}, \lambda=85^{\circ}$; this mechanism is an average of the results of other studies of this event using long-period surface waves and teleseismic body waves. The mean rupture velocity is $2.7 \mathrm{~km} / \mathrm{sec}$ and the standard deviation $0.2 \mathrm{~km} / \mathrm{sec}$. The $m_{i j} \mathrm{~s}$ are chosen so that the fault plane contains the moment distribution found by virtually all studies of the long-period or broadband teleseismic records of this event; that is, two large asperities separated by about 80 to $90 \mathrm{~km}$ (see, for example, Houston and Kanamori, 1986b, 1990). The moment, or strength, of a subfault in the asperity region is seven times greater than that of a subfault in the weak zone. We needed to have such strong asperities in order that $A_{\text {tele }}(t)$ in Figure 13 would correspond closely to the teleseismic time function of the 1985 Michoacán earthquake (Fig. 1). In Figure 13 the shapes of the rupture functions, $A_{\mathrm{sm}}(t)$, vary significantly for the four stations. This variation is due to the interference of radiation from the two widely separated subevents. This interference depends on station azimuth and distance and results in significant changes in the signal duration as a function of azimuth.

Figure 14 shows a comparison of the observed strong-motion spectra with the spectra estimated from the teleseismic source spectrum, assuming a point source (e.g., equation (2)) and assuming a finite source (e.g., equation (4)). Correcting for the finite fault with equation (4) yields only a small improvement of our estimates of strong-motion amplitudes. The spectral shapes still do not agree in detail, probably because the structure through which the strong motions propagate is more complicated than a half-space and because site response was not included.

Although the rupture functions are different for the four nearby stations, the main differences (e.g., the differences between their durations and overall shapes) occur at periods longer than $20 \mathrm{sec}$. These differences in duration produce a change in spectral shape analogous to a corner frequency shift. Therefore, the differences between the spectra estimated using the rupture functions to correct for the finite source and the spectra estimated using a point source model occur at relatively long periods and are not prominent in Figure 14. The fact that correcting for a finite source does not make a large difference in the absolute level of the spectra

\section{Michoacan Earthquake Strong Motion Spectra}
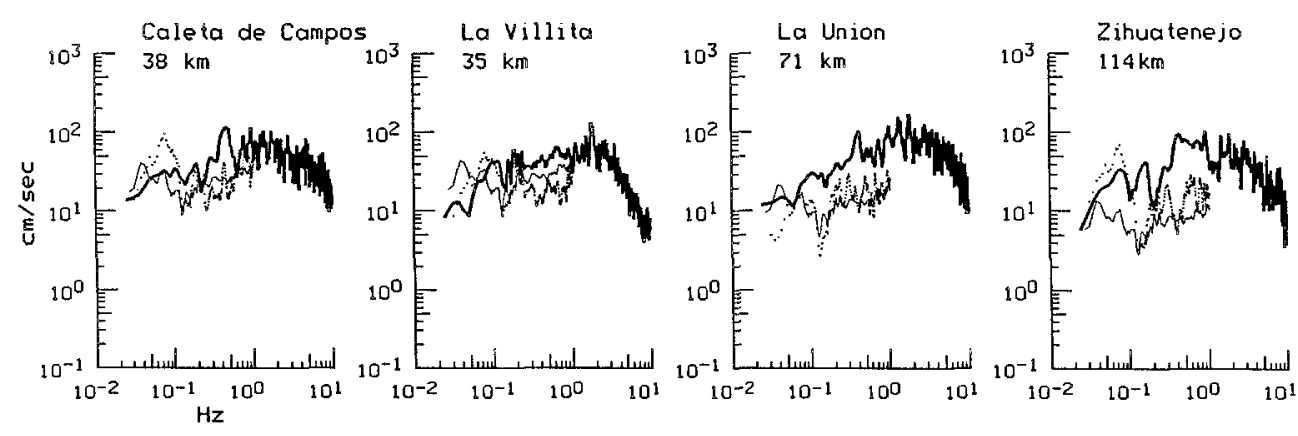

FIG. 14. Acceleration spectra of the 1985 Michoacán, Mexico earthquake for four stations near the fault plane. The thick lines show the spectra of the strong-motion data. The thin lines show the acceleration spectra estimated from the teleseismic source spectrum using equation (2), which assumes a point source at the distance shown in each panel. The dotted lines show the spectra estimated from the teleseismic source spectrum and corrected for a finite source using equation (4). 
in Figure 14 illustrates that the distance to the center of the fault plane, $r_{o}$, used in equation (2) represents a reasonable average value.

In the above calculations, we used the far-field approximation and neglected any near-field contribution that may have been present. For a point source, the nearand far-field displacements from a double couple are proportional to $M_{o} / 4 \pi \mu r^{2}$ and $\dot{M}_{o} / 4 \pi \mu \beta r$, respectively, where $\mu$ is the rigidity. Thus, the relative importance of the near- and far-field terms is determined approximately by the ratio, $\beta / \omega r$, of the above two terms. If $r$ is larger than $30 \mathrm{~km}$, the ratio is less than $1 / 60$ and $1 / 6$ at 1 and $0.1 \mathrm{~Hz}$, respectively. Thus, for most stations used in this study, we estimate that the near-field contribution is not significant for our computations at frequencies greater than $0.05 \mathrm{~Hz}$. However, for Caleta de Campos and La Villita for the Mexican earthquake, the near-field term may be significant even at $0.1 \mathrm{~Hz}$.

\section{Discussion}

We interpret the difference between the observed and the reference spectra as due to complex propagation and site effects. Below, we examine the relationship between the observed and reference spectra, the distance, and the site condition. If empirical relationships between these factors can be established, they can be used to estimate strong-ground motions from the teleseismic source spectrum as a function of distance and site condition.

Figure 15 summarizes the results of Figures 10, 11, 12, and 14 for two frequencies, 1 and $0.5 \mathrm{~Hz}$. We plot the ratio of observed to reference spectral amplitude of ground acceleration versus distance from the source to the station using equations (2) and (4). In Figure 15, open squares represent hard sites, closed squares represent soft sites, and partially filled squares represent intermediate sites. Squares with $x$ 's in them represent ratios calculated using equation (4) for the finite fault. Scatter is large, especially for the Valparaiso and Akita-Oki earthquakes. A clear trend is the increasing ratio of observed to reference spectral amplitudes with increasing distance. The ratio increases from about 1 or 2 at distances less than $100 \mathrm{~km}$ to 10 at distances of 200 to $300 \mathrm{~km}$. As mentioned above, this is probably due mainly to the development of surface waves at greater distances. It could also be due partly to different actual attenuation than that assumed $(Q=300)$. Examination of the entire frequency band between 1 and $0.5 \mathrm{~Hz}$ in the spectra in Figures 10, 11, 12, and 14 indicates that even for the closer strong-motion stations our simple half-space model (including the extended source model) generally underestimates the observed spectra by a factor of about 2. We interpret this as due to site effects and to the effects of wave propagation through velocity structures that are more complicated than the half-space we assumed. It is interesting that correcting for the finite fault with equation (4) (indicated by the squares with $x$ 's in Figure 15) yields a only a small improvement of our estimates of strong-motion amplitudes. This suggests that the discrepancy is due to inadequate modeling of site effects, attenuation, or propagation through complex velocity structures, and not to the finite extent of the fault.

All of the Mexican (Guerrero) accelerometers used in this study are located on hard sites (J. Anderson, personal communication). Of the Chilean accelerometers, stations Melipilla, Valparaíso UFSM, Vina del Mar, Pichilemu, and Los Vilos are located on hard sites, while station Iloca is on an intermediate site, and the other Chilean stations are on soft sites (Celebi 1988). Of the Japanese accelerometers, the closest station, FRF, is sited on hard rock, while stations AOM, AKI, HAK, HACK, 
Ratio of Observed to Estimated Spectral Amplitudes

1985 Michoacan, Mexico Strong Motions
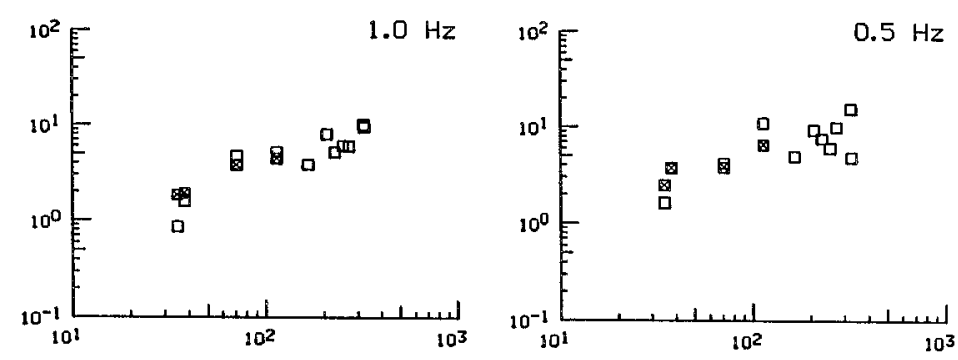

1985 Valparaiso, Chile Strong Motions
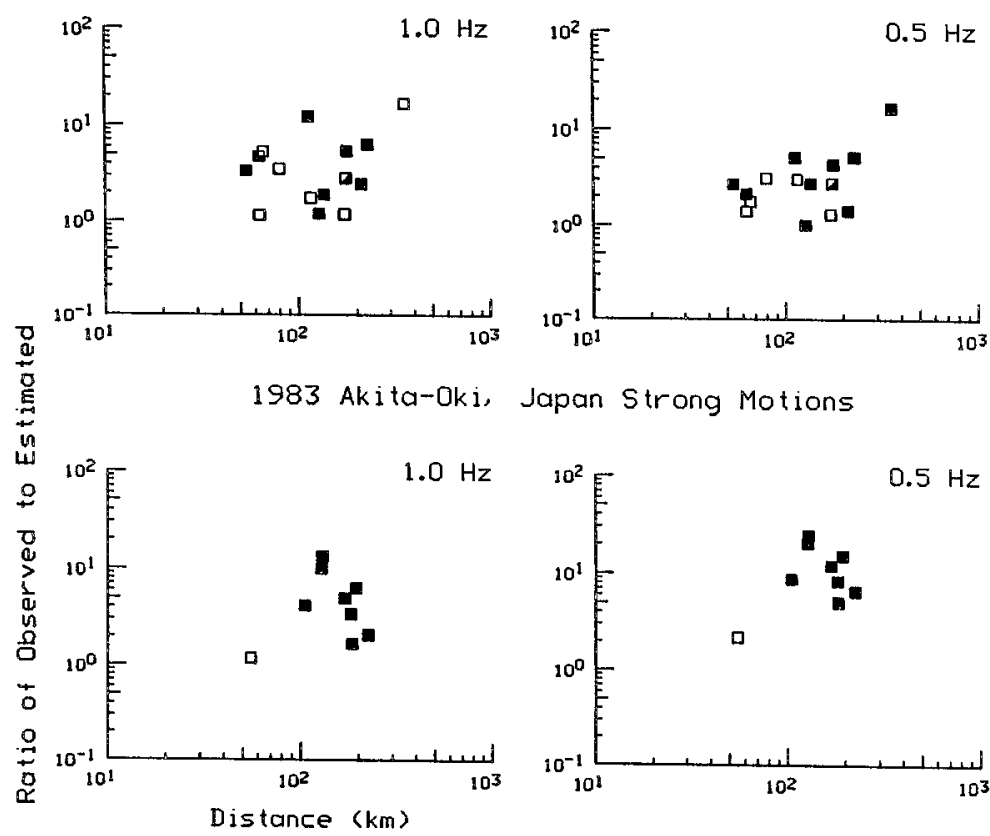

Japan Strong Motions

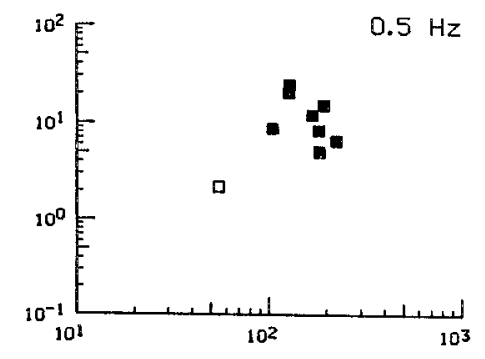

FIG. 15. The ratios of the observed to estimated spectral amplitudes of strong motions versus distance from the center of the fault plane to the station at $1.0 \mathrm{~Hz}$ and $0.5 \mathrm{~Hz}$. Open squares represent hard sites; closed squares represent soft sites; and partially filled squares represent intermediate sites. For the Michoacan earthquake the squares with x's inside indicate that the estimated spectral amplitudes were corrected for the finite fault plane using equation (4).

SAK, and MUR are located on soft, alluvial sites, according to C. B. Krouse (personal communication) and stations HRD, AOM, AKI, HAK, SRN, SAk, and MUR have amplification factors of 2 to 5 compared to FRF, according to Sato (1985). For the Valparaiso earthquake a correlation between soft site geology and relatively high strong-motion spectra can be seen in Figures 11 and 15.

Consider only hard sites at distances less than $100 \mathrm{~km}$, where the assumptions of the reference model are most justified. This includes Caleta de Campos, La Villita, La Union, and Zihuateneho for the Michoacán earthquake, FRF (Furofushi) for the Akita-Oki earthquake, and Melipilla, Valparaíso UFSM, Vina del Mar, and 
Pichilemu for the Valparaiso earthquake. Other hard sites within $100 \mathrm{~km}$ of the source for which a comparison has been made between strong-motion spectra and teleseismic source spectra of large earthquakes include site EO2 in the SMART array in Taiwan, which recorded the 1986 Taiwan earthquakes (Hwang and Kanamori, 1989), a site on Adak Island which recorded the 1986 Andreanof Island earthquake (L. Hwang, personal communication), and three accelerographs which recorded the 1985 Nahanni earthquakes (Choy and Boatwright, 1988). For all these hard sites, the actual strong-motion spectra are a factor of 1 to 3 times larger than the reference spectra.

In order to check the possible effect of radiation pattern on these strong motions, we calculated spectra using equation (2) with the radiation pattern $R_{\theta \phi}^{S}$ relative to the center of the fault equal to the actual radiation pattern for each station, rather than the average value 0.63 . We then examined plots analogous to those in Figure 15. Using the actual total $S$-wave radiation pattern in the point source model didn't improve the estimate significantly or reduce the scatter between stations at frequencies of 1 and $0.5 \mathrm{~Hz}$ compared to using the average $S$-wave radiation pattern 0.63 . In particular, for the Michoacán earthquake, using the actual radiation pattern rather than the average one decreased our estimates of the spectral amplitudes significantly at larger distances, because all the distant stations except Teacalco lie near a node of the total $S$-wave radiation pattern and have an actual radiation pattern of about 0.12 . Thus, using the actual radiation pattern for Figure 10 would increase the discrepancy between the observed and reference spectra. Since use of the actual radiation pattern doesn't improve the estimate or reduce the scatter, it appears that use of an average radiation pattern is justified.

\section{CONCLUSIONS}

We analyzed strong-motion spectra observed for three large subduction earthquakes. The decay of spectral amplitudes of acceleration with distance from the center of the fault plane is significantly different for these three events. The Michoacán earthquake generally had the lowest spectral amplitudes and the slowest decay with distance, while the Valparaiso earthquake had the highest amplitudes. The Akita-Oki earthquake is an intermediate case.

Teleseismic broadband records available for these earthquakes from GDSN yield average source spectra that are significantly different from each other. We scaled the teleseismic source spectra to produce reference strong-motion spectra at periods from 1 to $20 \mathrm{sec}$, assuming that the strong motions consist of $S$ body waves from a point source recorded at the surface of a homogeneous half-space, and that the farfield approximation applies. For all three earthquakes the reference spectral amplitudes at periods of 1 to $5 \mathrm{sec}$ are about half the observed ones at distances of about $50 \mathrm{~km}$. The differences increase as the distance increases. At distances of 200 to $300 \mathrm{~km}$, the reference spectrum is about $1 / 10$ of the observed one.

For the four stations closest to the Michoacán earthquake at which body waves are expected to predominate, we corrected the spectra for the finiteness of the source. To make this correction we divided the dipping, two-dimensional fault into small subfaults, which were assumed to be point sources, and allowed rupture to propagate across the fault plane with some randomness. Two regions of greater moment release (e.g., asperities) were included, as found by other studies of the Michoacán earthquake. Applying our correction for fault finiteness yields only a small improvement in our estimates of strong-motion spectra. The spectral shapes still do not agree in detail. This suggests that the differences between the observed 
and reference spectra are due to the contribution of phases other than direct $S$ waves and to site response, and not to the finite extent of the fault. With more results such as these to calibrate the relationship between the observed and reference spectra as a function of distance and site condition, teleseismic records of large earthquakes, which are more abundant than strong-motion records, may be used to estimate characteristics of strong motions from large earthquakes.

\section{ACKNOWLEDGMENTS}

Accelerograms from the Guerrero accelerometer array were made available by John Anderson and the Institute of Geophysics and Planetary Physics of the University of California, San Diego and the Instituto de Ingenieria at the Universidad Nacional Autonoma de Mexico, Mexico City. T. Sato provided strong-motion data from the Akita-Oki earthquake, which were used with the permission of the Port and Harbor Research Institute (stations AKI, AOM, HAK, SAK, MUR, and HAC), the Central Research Institute of the Electric Power Industry (stations FRF and SRN), and Hirosaki University (station HRD). E. Kausel provided strong-motion data from the Valparaiso earthquake recorded by accelerometers operated by the Department of Geophysics at the University of Chile. P. Mork, M. Celebi, and G. H. Saragoni made available strong-motion data from accelerometers operated by the Department of Civil Engineering at the University of Chile. The paper was reviewed by D. Boore and J. Boatwright. This research was partially supported by NSF grants ECE-86-10994 and EAR-87-21190, USGS Grant 14-08-0001-G1773, and the W. M. Keck Foundation. This is contribution No. 90 of the Institute of Tectonics and C. F. Richter Seismological Laboratory.

\section{REFERENCES}

Anderson, J. G., P. Bodin, J. N. Brune, J. Prince, S. K. Singh, R. Quaas, and M. Oñate (1986). Strong ground motion from the Michoacán, Mexico earthquake, Science 233, 1043-1049.

Burger, R. W., T. Lay, and L. J. Burdick (1987). Average $Q$ and yield estimates from the Pahute Mesa test site, Bull. Seism. Soc. Am. 77, 1274-1294.

Brune, J. N. (1970). Tectonic stress and the spectra of seismic shear waves from earthquakes, J. Geophys. Res. 75, 4997-5009.

Castro, R. R., J. G. Anderson, and S. K. Singh (1990). Source functions, site response, and spectral attenuation of $S$ waves along the Guerrero, Mexico subduction zone, Bull. Seism. Soc Am. (in press).

Celebi, M. (1988). Processed Chile earthquake records of 3 March 1985 and aftershocks, U.S. Geol. Surv. Open-File Rept. 87-195.

Choy, G. L. and J. Boatwright (1988). Teleseismic and near-field analysis of the Nahanni earthquakes in the Northwest Territories, Canada, Bull. Seism. Soc. Am. 78, 1627-1652.

Choy, G. L., and V. F. Cormier (1986). Direct measurement of the mantle attenuation operator from broadband $P$ and $S$ waveforms, $J$. Geophys. Res. 91, 7326-7342.

Der, Z. A. and A. C. Lees (1985). Methodologies for estimating $t^{*}(f)$ from short-period body waves and regional variations of $t^{*}(f)$ in the United States, Geophys. J. R. Astr. Soc. 82, 125-140.

Heaton, T. H., F. Tajima, and A. Wildenstein-Mori (1986). Estimating ground motions using recorded accelerograms, Surveys in Geophysics 8, 25-83.

Houston, H. (1987). Source characteristics of large earthquakes at short periods, Ph.D. Thesis, California Institute of Technology, Pasadena, California, 129 pp.

Houston, H. and E. R. Engdahl (1989). A comparison of the spatio-temporal distribution of moment release for the 1986 Andreanof Islands Earthquake with relocated seismicity, Geophys. Res. Lett. 16, 1421-1424.

Houston, H. and H. Kanamori (1986a). Source spectra of great earthquakes: teleseismic constraints on rupture process and strong motion, Bull. Seism. Soc. Am. 76, 19-42.

Houston, H. and H. Kanamori (1986b). Source characteristics of the 1985 Michoacán, Mexico earthquake at periods of 1 to 30 seconds, Geophys. Res. Lett. 13, 597-600.

Houston, H. and Kanamori (1990). Broadband rupture processes of four large subduction zone earthquakes: spatial distribution of seismic moment release (submitted for publication).

Hwang, L. J. and H. Kanamori (1989). Teleseismic and strong-motion source spectra from two earthquakes in Eastern Taiwan, Bull. Seism. Soc. Am. 79, 935-944.

Kanamori, H. and L. Astiz (1985). The 1983 Akita-Oki earthquake $\left(M_{w}=7.8\right)$ and its implications for systematics of subduction earthquakes, Earthq. Predict. Res. 3, 305-317. 
Kikuchi, M. and Y. Fukao (1987). Inversion of long-period $P$ waves from great earthquakes along subduction zones, Tectonophysics 144, 231-247.

Kikuchi, M. and H. Kanamori (1982). Inversion of complex body waves, Bull. Seism. Soc. Am. 72, $491-506$.

Sato, T. (1985). Rupture characteristics of the 1983 Nihonkai-Chubu (Japan Sea) earthquake as inferred from strong-motion accelerograms, J. Phys. Earth. 33, 525-557.

INSTITUTE OF TECTONICS

University of California, Santa Cruz

Santa Cruz, California 95064

(H.H.)

Manuscript received 30 May 1989

\author{
SEISMOLOGICAL LABORATORY \\ California Institute of TeChNOlogy \\ Pasadena, CaLIFornia 91125 \\ (H.K.)
}

